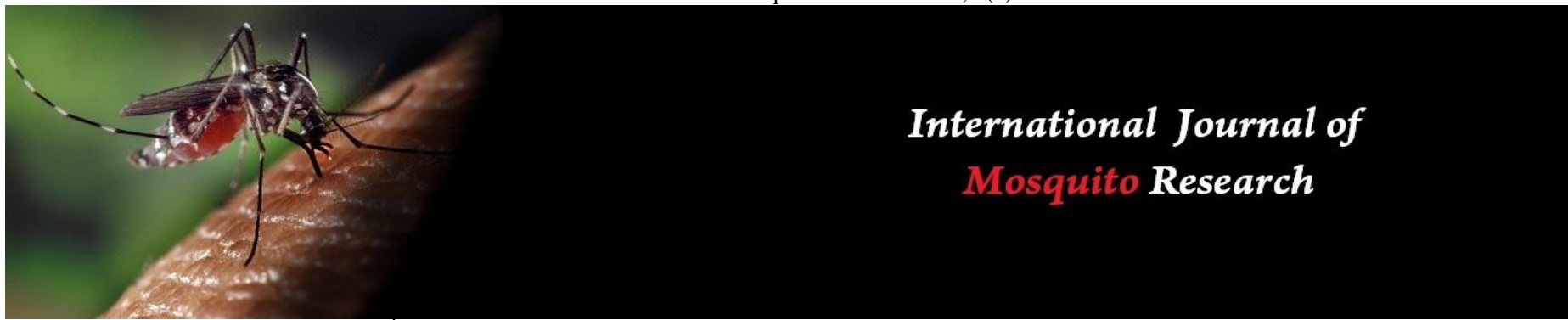

ISSN: 2348-5906

CODEN: IJMRK2

IJMR 2022; 9(1): 32-37

(C) 2022 IJMR

www.dipterajournal.com

Received: 13-11-2021

Accepted: 15-12-2021

\section{Suraj Chetri}

Department of Zoology,

Cotton University, Assam, India

Lupamudra Borah

Department of Zoology,

Cotton University, Assam, India

Sasanka Sekhar Ghosh

Department of Zoology,

Cotton University, Assam, India

Rezina Ahmed

Department of Zoology,

Cotton University, Assam, India

Parag Deka

Department of Zoology,

Pandu College, Assam, India

Corresponding Author: Sasanka Sekhar Ghosh Department of Zoology, Cotton University, Assam, India

\section{Larvicidal efficacy of Azadirachta indica (Neem) and Curcuma longa (Turmeric) on larvae of culex: An in silico approach}

\author{
Suraj Chetri, Lupamudra Borah, Sasanka Sekhar Ghosh, Rezina Ahmed \\ and Parag Deka
}

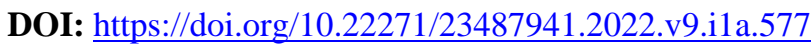

\section{Abstract}

Culex is a genus of mosquitos responsible for the transmission of various vector-borne diseases in humans. They spread diseases like Japanese encephalitis, West Nile fever, St. Louis encephalitis, Filariasis, etc. The present study focuses on the larvicidal activity of botanical products in the control of these disease vectors. Azadirachta indica (Neem) and Curcuma longa (Turmeric) are used for the insilico analysis of their action as larvicides. The larvicidal activity of the test extracts are also studied through larval toxicity tests. A comparative analysis of the results is prepared to understand the effect of Neem and Turmeric in the biocontrol of the target species.

Keywords: alpha amylase, bio control, glutathione s transferase, larvicides, mosquito

\section{Introduction}

Mosquito-borne diseases are predominant in more than 100 nations across the world, consistently contaminating north of 700,000,000 individuals universally and 40,000,000 of the Indian populace ${ }^{[1]}$. Mosquitoes carry serious vector-borne diseases such as dengue, malaria, Japanese encephalitis, hemorrhagic fever, filariasis, etc., responsible for killing millions of people each year ${ }^{[2]}$. Broad utilization of insecticides or substance insect poisons for control of vector-borne infections has led to issues such as physiological resistance of vectors, antagonistic ecological impacts, and high functional expense etc ${ }^{[3]}$. Because of widespread insecticide resistance in mosquitoes ${ }^{[4]}$, consideration has been pulled together towards the preDDT period control apparatuses including larval control and environmental management ${ }^{[5,6]}$. Considering this, the use of eco-accommodating options such as organic control of vectors has turned into the focal point of the control program. Nonchemical larval control may include botanical larvicides ${ }^{[7]}$, natural predators ${ }^{[8,9]}$, pathogenic fungi ${ }^{[10]}$. But no matter which method is used, it is important to determine whether mosquitoes will continue to oviposit in treated larval habitats ${ }^{[11]}$. Plants produce numerous chemicals, many of which have medicinal and insecticidal properties. More than 2000 plant species have been known to produce chemical factors and metabolites of value in pest control ${ }^{[1]}$. Plant species belonging to families such as Solanaceae, Asteraceae, Cladophoraceae, Labiatae, Miliaceae, Oocystaceae, and Rutaceae have shown to have larvicidal, adult killing or repellent activities against different species of mosquitoes ${ }^{[7]}$. Botanical larvicides derived from Azadirachta indica and Curcuma longa (Turmeric) are known to show considerable success in the control of mosquito vectors [12-14].

Based on available literature, the plant phytochemicals of Neem and Turmeric were thus used for in silico analysis of their effect on the target species. In-silico analysis in drug design allows a more precise and fast understanding of the interactions of the test molecules with the target receptors. Similar computer-based methods are used to study the interactions of the phytochemicals present in neem and turmeric with the receptors of the target species. A list of plant phytochemicals was prepared from available literature ${ }^{[15-17]}$. The receptors were selected based on their function in the biochemical processes of the target organism. For the current study, Glutathione S Transferase and Alpha-Amylase were chosen as target receptors. 
Glutathione S Transferase is an enzyme that contributes to the detoxification of xenobiotics in Insects ${ }^{[18]}$. Alpha-amylase on the other hand is an enzyme that hydrolyses polysaccharides such as starch and glycogen and helps the insect in the digestion of food. Further, larval toxicity tests were performed in the laboratory and the results were analyzed to prepare a comprehensive comparison between Neem and Turmeric as botanical larvicides in biocontrol of Culex mosquitos.

\section{Materials and Methods}

\subsection{Preparation of Receptor and Ligand}

The receptors, Glutathione S Transferase and Alpha amylase
(Fig 1) are selected and their corresponding. pdb files are downloaded from RCBS PDB Database ${ }^{19}$ (https://www.rcsb.org/). The database is a collection of 3D structural data of different large biological molecules such as proteins and nucleic acids ${ }^{20}$. The phytochemical constituents of Azadirachta indica (Neem) and Curcuma longa (Turmeric) were compiled through the study of previously available literature. Accordingly, the ligands were selected and their structures were downloaded from Zinc Database ${ }^{21}$ (https://zinc.docking.org/).

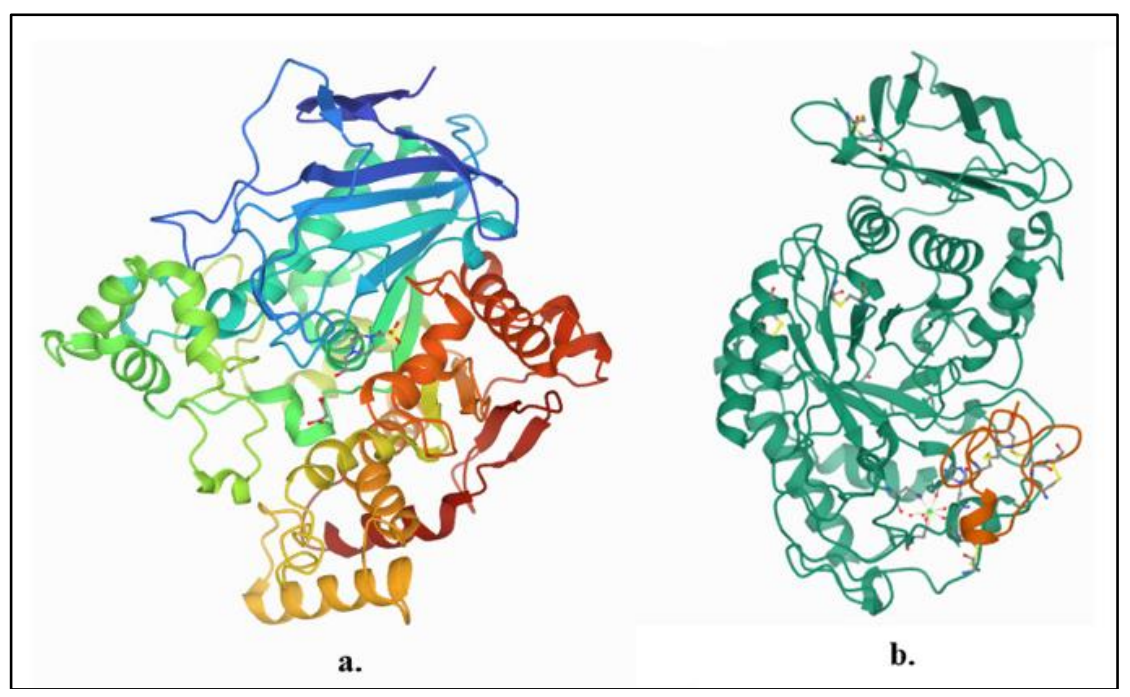

Fig 1: Structure of Enzymes: (a) Glutathione S Transferase, (b) Alpha amylase

\subsection{Molecular Docking}

Molecular docking is a tool used in drug design to study receptor-ligand interactions ${ }^{[22]}$. Docking was performed by using the software, Molegro Virtual Docker (MVD 2010.4.0) for Windows. MVD predicts receptor-ligand interactions by using different ligand binding conformations and estimating energy of their interactions ${ }^{[23]}$.

\subsection{Visualizing the Receptor Ligand Interactions}

The receptor-ligand interactions are visualized using BIOVIA Discovery Studio Visualizer developed by Dassault Systems BIOVIA 2021. This is a free software used for visualizing and analysis of protein and small molecular data. The software allowed us to study the interactions of the ligand molecules with the amino acid residues of the target proteins. Only the top 3 interacting molecules were used for further study. The interactions are displayed using both 3D and 2D models.

\subsection{Toxicity Tests (Wet Lab analysis)}

Neem leaves were collected and air dried under shade for 6-7 days. After which it was subjected to treatment in an incubator at $60{ }^{\circ} \mathrm{C}$ for 48 hours. Fully dried leaves were then ground in a grinder to obtain neem powder. Raw turmeric was allowed to dry at room temperature for 1-2 months and crushed by an electrical blender to produce a powder. The ethanolic extracts of plant material was prepared in a 1:100 $(\mathrm{w} / \mathrm{v})$ ratio. The extracts were filtered through a Buchner funnel with Whatman number 1 filter paper and the filtrate

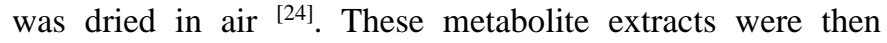
dissolved in ethanol to obtain a final concentration of 1000 $\mathrm{mg} / \mathrm{l}$ as a stock plant extract. Four test concentrations (50,
100, 500, and $1000 \mathrm{ppm}$ ) were prepared through a single dilution method and stored in labeled specimen bottles for larvicidal bioassay. The larvicidal activity was done as per guidelines of WHO ${ }^{[25]}$ and Khanra et al., 2015 ${ }^{[24]}$. The mosquito larvae were treated with different concentrations of plant extract. After $24 \mathrm{~h}$ and $48 \mathrm{~h}$ count, the number of dead larvae (mortality) was calculated against an untreated control by the following formula ${ }^{[26]}$

$\%$ of Mortality $=($ Mortality in treatment $/$ Mortality in control $)$ X 100

\section{Results}

The larvicidal efficiency of both Neem and Turmeric were studied using in-silico techniques and then verified through toxicity tests. The mean re-rank scores of all the interactions were then combined to prepare a graphical representation of the effect of different plant phytochemicals against the selected enzymes. The re-ranking coefficients uses different energy parameters such as E-Inter total, E-Inter (proteinligand), Steric, Van der Waal's, H-Bond energy, etc. A negative re-rank score signifies a good interaction between the phytochemicals and the active site of ligand (Enzyme) of interest. The blocking of the active sites of these ligands with phytochemicals taken for study can be helpful in disrupting the normal functioning of enzymes ultimately affecting the normal functioning of the insect physiology. From the Neem plant, 8 phytochemicals viz. 1, 2-benzendicarboxylic acid, Quercetin, Gedulin, Phytol, Sitosterol, Azadirachtin, Salanin and Nimbin were taken for in silico study. Among all the phytochemicals, Phytol shows minimum re-rank score of - 
77.73 signifying highest binding potential against enzyme $\alpha$ amylase. 1, 2-benzenedicarboxylic acid shows minimum rerank score of -68.68 against enzyme Glutathione $\mathrm{S}$ Transferase. From the Turmeric plant, 8 phytochemicals, viz. Ar-Turmerone, Bisdemethoxycurcumin, Curcumin, Curcuphenol, Curlone, Demethoxycurcumin, Turmerone and Zingiberene were taken for in silico study. Among all the phytochemicals Curcumin shows minimum re-rank score of $91.47 \&-82.09$ against enzymes $\alpha$-amylase and Glutathione $S$ Transferase respectively (Fig.2 \& 3). The interactions of the phytochemicals with the selected enzymes were analyzed and several interactions like $\mathrm{H}-\mathrm{Bond}, \mathrm{C}-\mathrm{H}$ bond, Van der Waals, alkyl bond, pi- alkyl bond etc. were found ' (Fig. 4 \& 5).

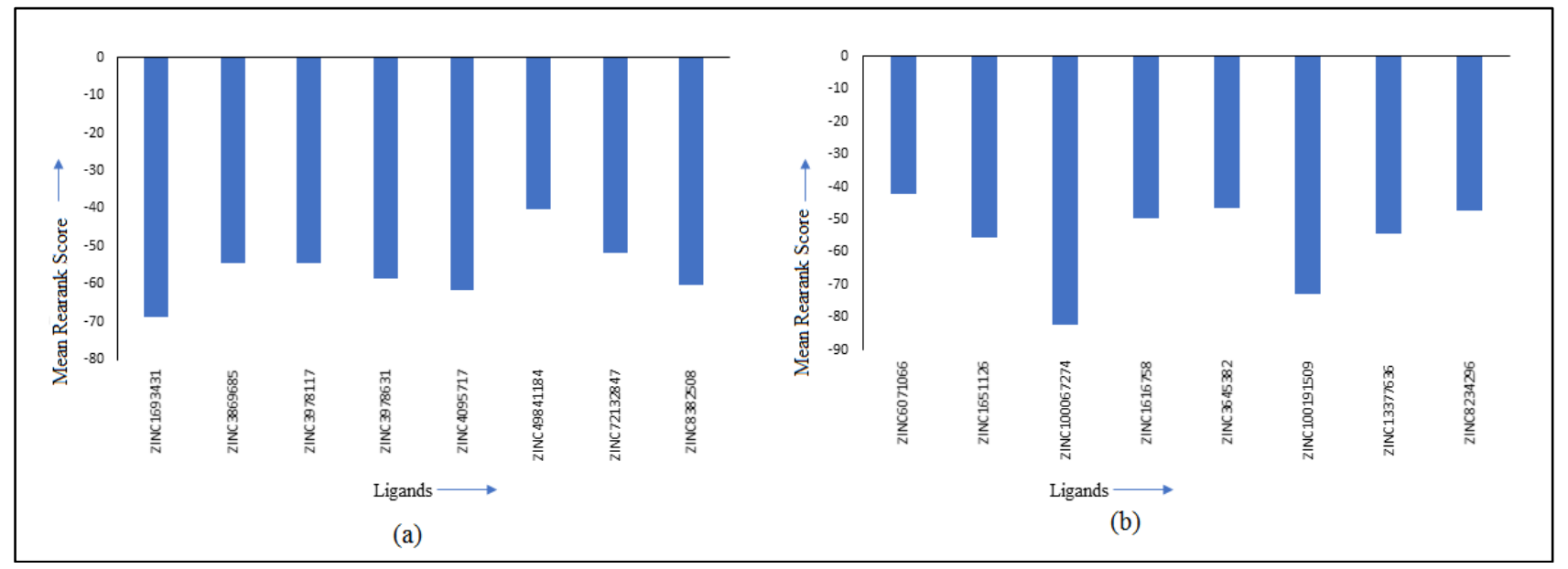

Fig 2: Graph showing rerank score of plant phytochemicals against Glutathione S Transferase: (a) Neem, (b) Turmeric

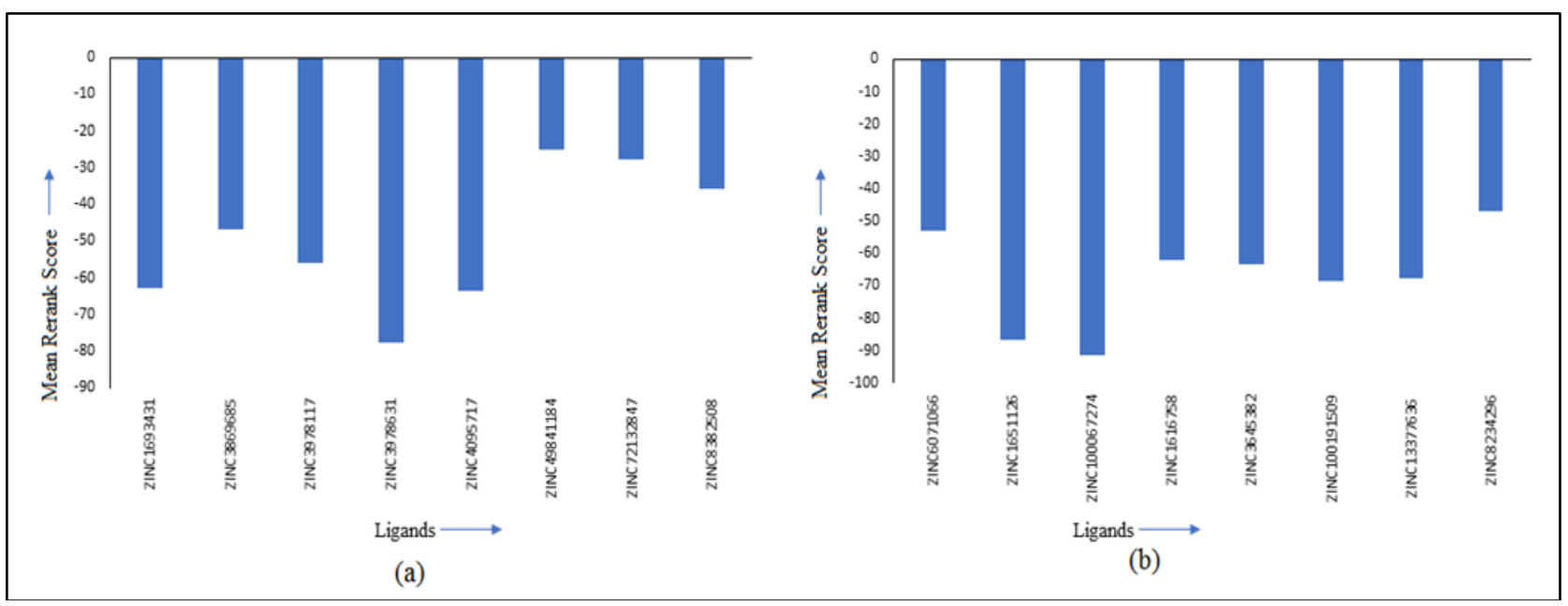

Fig 3: Graph showing Rerank score of plant phytochemicals against Alpha amylase: (a) Neem, (b) Turmeric

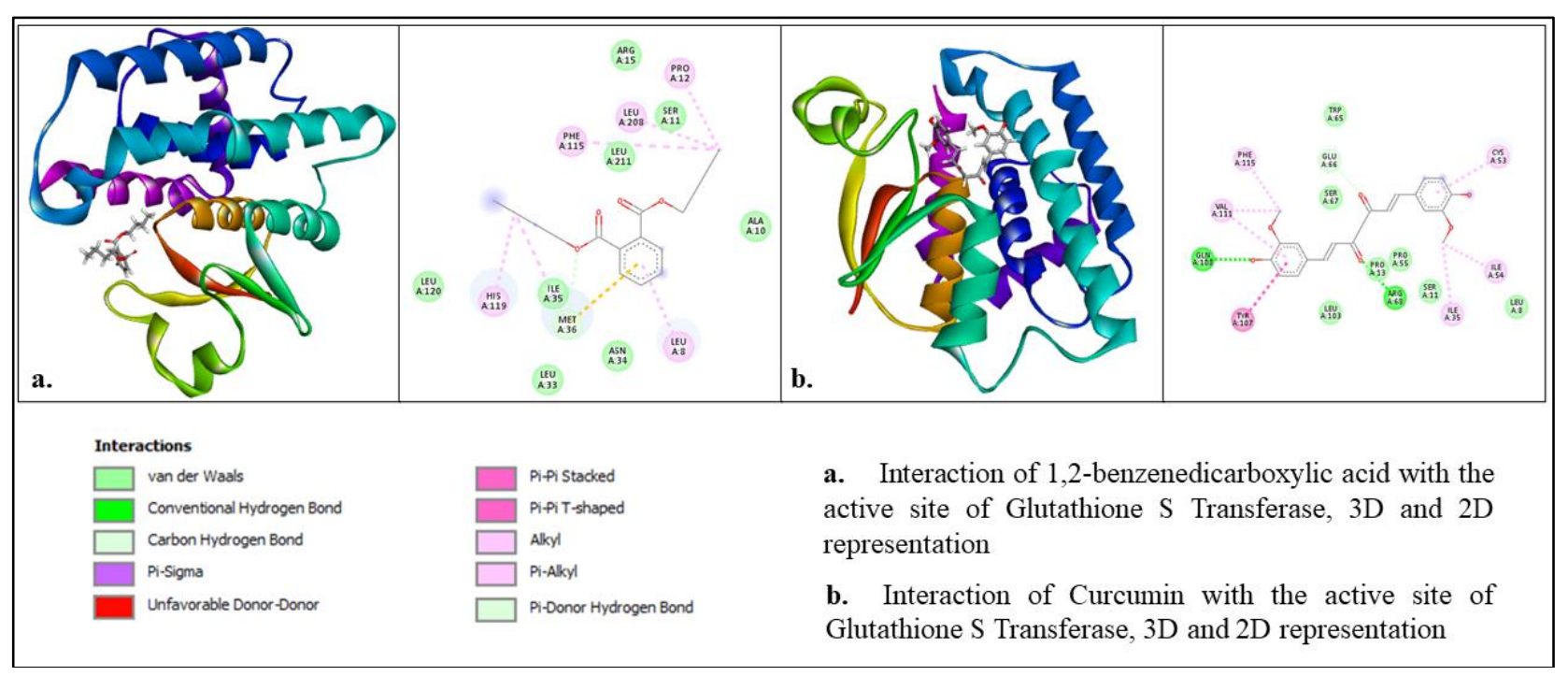

Fig 4: The Best Interaction observed with Glutathione S Transferase w.r.t. (a) Neem \& (b) Turmeric 


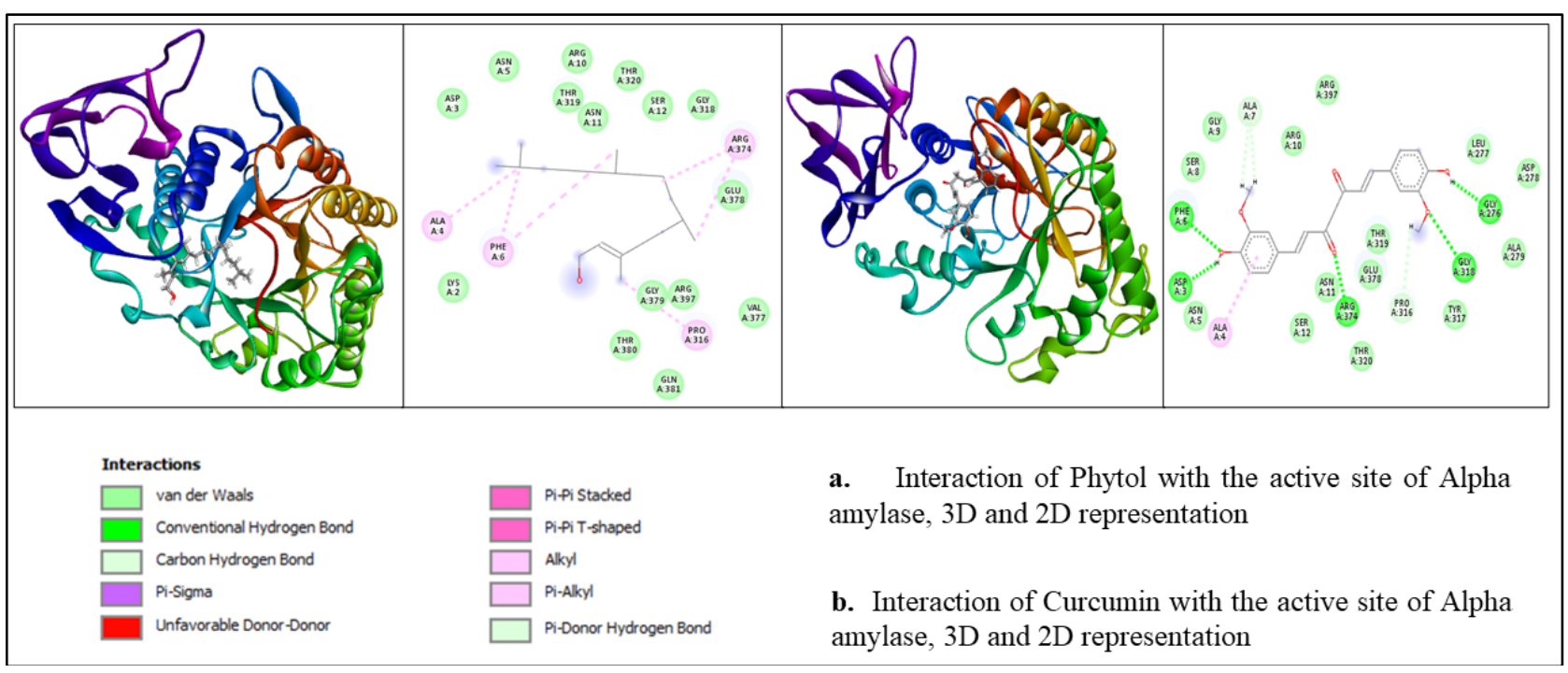

Fig 5: The best interaction observed with Alpha amylase w.r.t. (a) Neem \& (b) Turmeric

The in silico study has also been tested in wet lab experiments. Wet lab analysis on the effect of Neem and Turmeric on larvae of Culex shows that the mortality rate of larvae is dose dependent and increases with the increase in concentration of plant extract. The larvicidal activity of different concentrations of leaf extracts are shown. After $48 \mathrm{~h}$ and concentration of $1000 \mathrm{ppm}$ all leaf crude extracts showed $90 \%$ to $100 \%$ mortality of larvae. Ethanol extracts of Azadirachta indica (Neem) could produce $100 \%$ mortality at the concentration of $500 \mathrm{ppm}$ upon $48 \mathrm{~h}$ of exposure (Table 1 $\& 2)$.

Table 1: Larval mortality \% of Neem Extract

\begin{tabular}{|c|c|c|c|c|}
\hline Concentration (PPM) & 24 hrs & $\mathbf{4 8}$ hrs & \multicolumn{2}{|c|}{ mortality \% } \\
\hline 50 & 2 & 13 & $10 \%$ & $65 \%$ \\
\hline 100 & 5 & 14 & $25 \%$ & $72 \%$ \\
\hline 500 & 15 & 20 & $75 \%$ & $100 \%$ \\
\hline 1000 & 16 & 20 & $80 \%$ & $100 \%$ \\
\hline
\end{tabular}

Table 2: Larvae mortality \% of Turmeric Extract

\begin{tabular}{|c|c|c|c|c|}
\hline Concentration (PPM) & 24 hrs & $\mathbf{4 8}$ hrs & \multicolumn{2}{|c|}{ mortality \% } \\
\hline 50 & 2 & 5 & $10 \%$ & $25 \%$ \\
\hline 100 & 5 & 7 & $25 \%$ & $35 \%$ \\
\hline 500 & 12 & 15 & $50 \%$ & $75 \%$ \\
\hline 1000 & 13 & 18 & $65 \%$ & $90 \%$ \\
\hline
\end{tabular}

\section{Discussion}

Glutathione transferases (GSTs) are a diverse family of enzymes found in insects. They play a key role in removing toxic xenobiotic compounds ${ }^{[27]}$, oxygen-free radical species produced through the action of pesticide ${ }^{[28]}$, and are also involved in intracellular transport, production of hormones and protection against oxidative stress ${ }^{[29]}$. GSTs can metabolize insecticides by facilitating their dehydrochlorination or by coupling with reduced glutathione, to produce readily excretable water-soluble metabolites. Thus, for a pesticide to be successful, it must be able to inhibit or overpower the working of Glutathione transferase (GSTs). The present investigation reveals that 1,2-benzene dicarboxylic acid from Azadirachta indica and Curcumin from Curcuma longa show a minimum re-rank score of 68.68 and -82.09 against enzyme Glutathione S Transferase respectively, thereby indicating their potential role as a biopesticide. $\alpha$-Amylases constitute a family of endoamylases that catalyze the hydrolysis of $\alpha$-D- $(1,4)$-glucan linkages in starch components, glycogen and other carbohydrates ${ }^{[30]}$. The enzyme plays a key role in the carbohydrate metabolism of insects ${ }^{[31]}$ and insects depend on their $\alpha$-amylases for survival. Recent research has shown that $\alpha$-amylase inhibitors from Phaseolus vulgaris seeds are detrimental to the development of insects ${ }^{[32,33]}$. An earlier in silico study by Nascimanto et al. ${ }^{[34]}$ on the inhibiting properties of Ric C1 \& Ric C3 from Ricinus communis seeds revealed them to be potent alpha-amylase inhibitors. In the present study, Phytol from Azadirachta indica shows a minimum re-rank score of -77.73 signifying the highest binding potential against enzyme $\alpha$-amylase and Curcumin from Curcuma longa shows a minimum re-rank score of 91.47 against enzyme $\alpha$-amylase. Thus, the active compounds derived from both Azadirachta indica and Curcuma longa exhibit good binding properties with Glutathione transferase (GSTs) and $\alpha$-amylase and thereby can act as a potent deterrent in insect development. The results obtained in silico are also corroborated by the results obtained from the wet lab, where after $48 \mathrm{~h}$ and at a concentration of $1000 \mathrm{ppm}$ all leaf crude extracts showed $90 \%$ to $100 \%$ mortality of larvae. Similar in silico works by Yadav et al. ${ }^{[35]}$ Mejia et al.

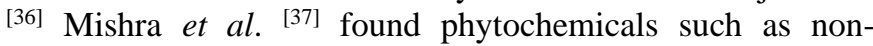
azadirachtin neem limonoids, phenylethanoid glycosides, biosynthesized AgNPs can block the enzymatic activities of acetylcholinesterase, prophenoloxidase, ecdysone receptor, and digestive enzymes of various insects, thereby acting as a good alternative to chemical pesticides. Works of Srinivasan

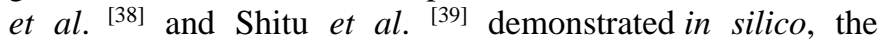
capability of compounds isolated from Citrus sinensis and Elaeagnus indica having the potential to be applied as a controlling agent of Anopheles mosquito.

All these results and the present in silico study signifies that both Azadirachta indica (Neem) and Curcuma longa (Turmeric) have larvicidal effect against larvae of Culex mosquito and can be used as alternatives to chemicals in controlling the larvae of Culex mosquito.

\section{Conclusion}

India, being a tropical country is wealthy in its biodiversity of plants species. Wet lab experiments for screening each and 
every plant extract against the test subject is not viable and time consuming. In silico identification approach slender down the search of the potential lead compounds from an enormous range of compound databases to pick potential hits by using molecular docking techniques and simplifying the interaction of potential hits that helps in optimization of bioactivity of the phytochemicals of the plant. In silico study is a recent development in the field of entomology where we can develop various effective biopesticides in a short span of time. Recent advancement in in silico analysis can be helpful in finding the best plant extract to be tested in web lab experiments and will also increase the chance to find most effective plant extracts to control the test subject within a short span of time and thus reducing the uncertainty on the outcomes, resulting in a faster and more efficient development of the pesticide. The study also points to this fact as the result obtained in the in silico analysis could be corroborated to the results obtained in wet-lab experiments.

\section{Acknowledgement}

The authors are thankful to Dr. Akalesh Kumar Verma, Department of Zoology, Cotton University, for providing access to the Molegro Virtual Docker software for the in silico work.

\section{References}

1. Ghosh A, Chowdhury N, Chandra G. Plant extracts as potential mosquito larvicides. The Indian Journal of Medical Research. 2012;135(5):581.

2. Kamaraj C, Bagavan A, Elango G, Zahir AA, Rajakumar $\mathrm{G}$, Marimuthu et al. Larvicidal activity of medicinal plant extracts against Anopheles subpictus \& Culex tritaeniorhynchus. The Indian Journal of Medical Research. 2011;134(1):101.

3. Brown AW. Insecticide resistance in mosquitoes: A pragmatic review. Journal of the American Mosquito Control Association. 1986;2(2):123-140.

4. Hemingway J, Ranson H. Insecticide resistance in insect vectors of human disease. Annual Review of Entomology. 2000;45(1):371-391.

5. Killeen GF, Fillinger U, Kiche I, Gouagna LC, Knols BG. Eradication of Anopheles gambiae from Brazil: lessons for malaria control in Africa. The Lancet Infectious Diseases. 2002;2(10):618-627.

6. World Malaria Report https://www.who.int/teams/global-malariaprogramme/reports/world-malaria-report-2021. 2021. December, 2021.

7. Shaalan EAS, Canyon D, Younes MWF, Abdel WH, Mansour AH. A review of botanical phytochemicals with mosquitocidal potential. Environment International. 2005;31(8):1149-1166.

8. Ghosh SK, Dash AP. Larvivorous fish against malaria vectors: a new outlook. Transactions of the Royal Society of Tropical Medicine and Hygiene. 2007;101(11):10631064.

9. Howard AF, Zhou G, Omlin FX. Malaria mosquito control using edible fish in western Kenya: preliminary findings of a controlled study. BMC Public Health. 2007;7(1):1-6.

10. Bukhari T, Middelman A, Koenraadt CJ, Takken W, Knols BG. Factors affecting fungus-induced larval mortality in Anopheles gambiae and Anopheles stephensi. Malaria Journal. 2010;9(1):1-15.

11. Howard AF, Guessan R, Koenraadt CJ, Asidi A, Farenhorst M, Akogbeto $\mathrm{M}$ et al. First report of the infection of insecticide-resistant malaria vector mosquitoes with an entomopathogenic fungus under field conditions. Malaria Journal. 2011;10(1):1-8.

12. Nour AH, Jessinta D, Nour AH. Larvicidal activity of extracts from different parts of neem (Azadirachta indica) against Aedes Aegypti mosquitoes larvae. Scientific Research and Essays. 2012;7(31):28102815.

13. Khanra K, Choudhuri I, Bhattacharyya N. Larvicidal Activity of Leaf Extract of Ginger and Turmeric on Mosquito Larvae. International Journal of Pharmaceutical Sciences and Research. 2018;9(5):2034-2036.

14. Dua VK, Pandey AC, Raghavendra K, Gupta A, Sharma T, Dash AP. Larvicidal activity of neem oil (Azadirachta indica) formulation against mosquitoes. Malaria Journal. 2009;8(1):1-6.

15. Cesa S, Sisto F, Zengin G, Scaccabarozzi D, Kokolakis AK, Scaltrito MM et al. Phytochemical analyses and pharmacological screening of Neem oil. South African Journal of Botany. 2019;120:331-337.

16. Srivastava SK, Agrawal B, Kumar A, Pandey A. Phytochemicals of Azadirachta indica source of active medicinal constituent used for cure of various diseases: A Review. Journal of Scientific Research. 2020;64(1):385390.

17. Sabir SM, Zeb A, Mahmood M, Abbas SR, Ahmad Z, Iqbal N. Phytochemical analysis and biological activities of ethanolic extract of Curcuma longa rhizome. Brazilian Journal of Biology. 2020;81:737-740.

18. Eaton DL, Bammler TK. Concise review of the glutathione $\mathrm{S}$-transferases and their significance to toxicology. Toxicological Sciences: An Official Journal of the Society of Toxicology. 1999;49(2):156-164.

19. Protein Structure Download. https://www.rcsb.org/. 25 November, 2021.

20. Parasuraman S. Protein Data Bank. The Journal of Pharmacology \& Pharmacotherapeutics. 2012;3(4):351352.

21. Ligands Structure Download. https://zinc.docking.org/. 27 November, 2021.

22. Ruyck J, Brysbeart G, Blossey R, Lensink MF. Molecular docking as a popular tool in drug design and in silico travel. Advances and Applications in Bioinformatics and Chemistry. 2016;9:1-11

23. Thomsen R, Christensen MH. MolDock: a new technique for high-accuracy docking. Journal of Medicinal Chemistry. 2006;49:3315-3321

24. Khanra K, Panja S, Choudhuri I, Bhattacharyya N. Antibacterial, insecticidal activity and cytotoxicity of methanol, ethanol, hot aqueous and cold aqueous extracts of Crotalaria juncia. International Journal of Current Research in Biosciences and Plant Biology. 2015;2(10):98-103.

25. WHO: Guidelines for Laboratory and Field Testing of Mosquito Larvicides. http://www.who.int/iris/handle/10665/69101. 3 October, 2021.

26. Rahuman AA, Gopalakrishnan G, Ghouse BS, Arumugam S, Himalayan B. Effect of Feronia limonia on 
mosquito larvae. Fitoterapia. 2000;71(5):553-555.

27. Salinas AE, Wong MG. Glutathione S-transferases-a review. Current Medicinal Chemistry. 1999;6(4):279310.

28. Pavlidi N, Vontas J, Van LT. The role of glutathione Stransferases (GSTs) in insecticide resistance in crop pests and disease vectors. Current opinion in Insect Science. 2018;27:97-102.

29. Enayati AA, Ranson H, Hemingway J. Insect glutathione transferase and insecticide resistance. Insect Molecular Biology. 2005;14(1):3-8.

30. Franco OL, Rigden DJ, Melo FR, Grossi MF. Plant $\alpha$-amylase inhibitors and their interaction with insect $\alpha$-amylases: Structure, function and potential for crop protection. European Journal of Biochemistry. 2002;269(2):397-412.

31. Da LJL. The amylases of insects. International Journal of Insect Science. 2018;10:1-14.

32. Ishimoto M, Kitamura K. Growth inhibitory effects of an $\alpha$-amylase inhibitor from the kidney bean, Phaseolus vulgaris (L.) on three species of bruchids (Coleoptera: Bruchidae). Applied Entomology and Zoology. 1989;24(3):281-286.

33. Shade RE, Schroeder HE, Pueyo JJ, Tabe LM, Murdock LL, Higgins TJ et al. Transgenic pea seeds expressing the $\alpha$-amylase inhibitor of the common bean are resistant to bruchid beetles. Biotechnology. 1994;12(8):793-796.

34. Nascimento VVD, Castro HC, Abreu PA, Oliveira AEA, Fernandez JH, Arauujo JDS et al. In silico structural characteristics and $\alpha$-amylase inhibitory properties of Ric c 1 and Ric c 3, allergenic 2S albumins from Ricinus communis seeds. Journal of Agricultural and Food Chemistry. 2011;59(9):4814-4821.

35. Yadav RP, Ibrahim KS, Gurusubramanian G, Kumar NS. In silico docking studies of non-azadirachtin limonoids against ecdysone receptor of Helicoverpa armigera (Hubner) (Lepidoptera: Noctuidae). Medicinal Chemistry Research. 2015;24(6):2621-2631.

36. Mejia MA, Salazar JR, Tejeda JF. In Silico studies on compounds derived from calceolaria: phenylethanoid glycosides as potential multitarget inhibitors for the development of pesticides. Biomolecules. 2018;8(4):121.

37. Mishra S, Wang W, Oliveira IP, Atapattu AJ, Xia SW, Grillo $\mathrm{R}$ et al. Interaction mechanism of plant-based nanoarchitectured materials with digestive enzymes of termites as target for pest control: Evidence from molecular docking simulation and in vitro studies. Journal of Hazardous Materials. 2021;403:123135.

38. Srinivasan R, Natarajan D, Shivakumar MS, Vinuchakkaravarthy T, Velmurugan D. Bioassay guided isolation of mosquito larvicidal compound from acetone leaf extract of Elaeagnus indica Servett Bull and its insilico study. Industrial Crops and Products. 2015;76:394401.

39. Shitu MI, Bello UR, Safiyan S. Molecular docking and ADMET properties of Citrus sinensis phytochemicals on insecticide resistance Anopheles gambiae: An in-silico analysis. Journal of Entomology and Zoology Studies. 2020;8(5):1030-1036. 